should not be done until at least half-an-hour after the birth of the child, and not then, unless the condition of the uterus and of the pulse is satisfactory.

Some modern authorities state that a binder is not necessary, and has no good effect in preserving the figure, but, even if that be granted, no one can deny that the binder has an immediate good effect in driving the blood from the large veins of the abdomen, and so preventing any tendency to cerebral anaemia, and this is particularly useful if the loss of blood has been at all great. I do not agree with the plan followed by some accoucheurs of putting a hard substance, as a book or pincushion, over the uterus before applying the binder.

There are some points in connexion with the manage ment of the puerperium to which I desire to call attention.

First, with reference to retention of urine, which not infrequently follows a prolonged or a forceps delivery before having recourse to the catheter, hot fomentations, preferably with antiseptic lotion, may be tried, and sometimes they are efficacious. If the catheter is required the question arises, Should it be passed by touch or by sight? I am strongly in favour of the latter plan, but, before giving my reasons, I should like, with your permission, to quote verbatim the directions given in Herman's First Lines in Midwifery, as this is a book extensively read by students and midwives:

To Pass a Catheter.-Place the patient on her back, with the knees drawn up. Cleanse the parts by gently wiping them with wool dipped in 1 in 2,000 sublimate solution. Take the catheter in the right hand, and hold it about 2 in. from the tip. (It is a good thing to put about $3 \mathrm{ft}$. of indiarubber tubing over the open end of the catheter; the urine is then conveyed out of the bed into a utensil on the floor.) Stand on the patient's right side, and pass the right hand holding the catheter under the patient's right thigh. Pass the left forefinger over the abdomen between the labia into the vagina. Then draw it upwards exactly in the middle line until the Then draw it upwards exactly in the middle line until the
pulp of the forefinger feels the orifice of the urethra. T'he meatus urinarius feels very like one of the small linen-covered buttons with which underclothing is of ten fastened: a littl ring, with a slight depression in its centre. When you feel this, draw the finger upwards till it is just above the meatus, and then with the right hand pass the point of the catheter below the tip of the left forefinger into the urethra. If you cannot succeed in thus quickly finding the meatus by the touch, it is better to look than to annoy the patient by protouch, it is better to look than to annoy the patient by p
longed attempts at passing the catheter by the touch alone.

The manœuvre above described is not easy to perform, and requires some practice; moreover, I venture to think that it is by no means the best way of passing the catheter, and that there are several objections to it.

In the first place, it increases the risk of cystitis, as it is impossible to be sure that the orifice of the urethra and its immediate neighbourhood have been wiped free from discharge unless they are clearly seen, and some of this may be carried into the bladder on the catheter.

Then, again, the manipulation about the external genitals introduces an added risk of septic infection, and as shown in Dr. Knyvett Gordon's paper, septic infection during the lying-in period is much more common than is usually supposed.

Before passing the catheter a clear view should always be obtained of the urethral orifice; this can be done with the patient lying on her back by separating the labia with the fore and middle fingers of the left hand. The urethral orifice and its neighbourhood should then be cleansed with an antiseptic, and the catheter, which is held in the right hand, inserted. It is, in my opinion, better to use a small basin to catch the urine than to attach a tube, as the latter makes the catheter more difficult to manipulate, and a further disadvantage is that it is not so easy to see if the urine is escaping properly.

A glass or metal catheter should be used; the latter is perhaps safer for a nurse's use, as cases have occurred in which a glass catheter has been broken during the movement of a restless patient. The catheter is best rendered aseptic by boiling.

It is a good plan to allow the patient's body to be lifted up in-bed into the vertical position, after the third or fourth day, for a few minutes daily, to facilitate the escape of the lochia. Care should be taken that the patient does not lie too persistently on the back, and she should be encouraged to lie on either side at intervals. There can be little doubt that many cases of retroflexion arise from the too persistent assumption of the dorsal decubitus during the puerperium.

As regards length of puerperium, I am accustomed to regard a fortnight as the minimum period after a normal confinement; few women realize the importance of sufficient rest after parturition.

My experience in the out-patient room has led me to the conclusion that almost all the cases of bad procidentia which are so numerous and so unsatisfactory in treatment are due to women getting up too soon after confinement and, whilst the uterus is heavy and its supports lax, doing hard work.

1 Journal of Obstetrice, May, 1905. 2 BRITISH MEdical JouRNat, March 10th, 1906. 3 Lancet. April 14th.

\section{A CASE OF BURROWING TUBO-OVARIAN CYST, WITH REMARKS ON ITS PATHOGENESIS.}

By W. SAMPSON HANDLEY, M.S., F.R.C.S.,

ASSISTANT SURGEON, THE MIDDLESEX HOSPITAL; LATE SURGEON TO OUT-PATIENTS, SAMARITAN FREE HOSPITAL.

IT is now well known, thanks to Dr. Cullingworth, that a hydrosalpinx may burrow in the broad ligament and may simulate a true broad-ligament cyst, and evidently that was the first event in the present case.

\section{History.}

M. T., aged 31, was admitted into the Samaritan Hospital under my care in January, 1903. Though married fo some years she has never been pregnant. Menstruation began at the age of 14 and continued regularly every month, the periods lasting three days. For the past two years, however she has sometimes menstruated at fortnightly intervals, and during the six months preceding operation the courses had lasted longer, once as long as sixteen days, and the menstrua fluid has become paler in colour. The amount of blood lost had not increased. Five years ago she began to suffer from pain in the lower part of the abdomen. She describes it as a dull, mild, aching pain, worse on the left side, and eased by lying down. During menstruation she had shooting pains in the hypogastric region. She has never noticed any increase in the size of the abdomen. Of late she has suffered severely from a feeling of pressure on the rectum. The bowel felt sore inside so that passed with great pain difficulty. She had never had retention of urine, but during the past year micturition had been frequent, and she had had to get up four or five times in the night to pass water. There and some loss of flesh.

\section{Condition on Admission.}

The patient was seen by my colleague, Mr. Corrie Keep. who diagnosed a broad ligament cyst, and advised operation. The abdomen was not markedly prominent. On palpation a median rounded tumour the shape of the pregnant uterus could be felt extending 2 in. above the umbilicus. Dullness extended from the pubes to the umbilicus. The tumour was slightly movable, and gave an indistinct thrill laterally. Vaginal examination showed that the tumour filled up the left fornix, and gave definite fluctuation when pressure was made on it with the abdominal hand. The right adnexa could not be felt from the vagina but on palpation by the rectum a not be felt from felt in the right fornix far back. It was softish mass was felt in the right fornix far back. It was tender on palpation, and seemed to have the size and shape of a hen's egg. On passing the sound its point could be felt at the right edge of the abdominal tumour just above Poupart's
ligament. The case was diagnosed as a left broad ligament cyst, with a smaller cyst on the right side.

\section{Operation.}

The abdomen was opened by a median 4 in. incision, and a left-sided cyst was exposed lying in the broad ligament, whose structures ran stretched out over the summit of the whose structures ran stretched out over the summit of the cyst. On tapping, about four pints of dark greenish-brown alkaline fluid escaped, of specific gravity 1015 , containing only now secured and cut through at the outer edge of the broad ligament, and a ligature was passed close to the left cornu including the Fallopian tube and uterine artery. The cyst had burrowed right up to the side of the uterus, and there was difficulty in passing this ligature without transfixing the was din the the outer side of the ligature. The round ligament was next the outer side of the ligature. The round ligament was next ligatured and cut through. Incisions through the peritoneum were now made, joining the three points of section of the ovarian artery, the Fallopian tube, and the round ligament in one complete annular incision surrounding the Fallopian enucleated from the broad ligament and the pelvic floor. 
The edges of the peritoneal capsule being held up by half a dozen pairs of forceps, a purse-string suture of silk was run
round the capsule some distance below its free peritoneal edge. The redundant capsule above the purse-string suture was dropped into the interior of the cavity left by the cyst, and the suture was tightened and tied. The bed of the cyst was now only indicated by a puckered depression in the peritoneum. This method can be recommended as a very rapid and effective way of closing the broad ligament after enuclea and effective way of closing the broad ligament after enucleation. It is, however, only possible when the tumour has considerably stretched the broad ligament. If the purse-string suture is passed sufficiently low a certain amount of tension is secured, which will assist in stopping oozing. No raw surface whatever is left which may become a source of adhesions. The redundant peritoneum which is dropped into the interior of the cavity must secure an abundant supply of plastic lymph to accelerate healing.

The small tumour formed by the right adnexa proved to be very adherent. It was after some difficulty brought up, transfixed by a double interlocked ligature in the ordinary way, and removed. The patient's recovery was uneventful. She has since menstruated only once, ten weeks after the operation, and at present, three years after it, is perfectly well.

The large tumour on the left side proved to be a tuboovarian cyst. The left tube, after running a course of about 3 in. from the uterus, opened into the cyst by an aperture the size of a threepenny-piece. The cyst itself was obviously not homogeneous in origin. The upper and inner part of its interior was yellowish in colour, and here and there atrophied plicae were visible. The outer portion of it was marked off quite sharply by its smoothness of surface and comparatively pale colour. The ovary was not to be found.

An examination of the right adnexa supplied the key to the pathology of the larger cyst. The outer portion of the right tube was distended into a hydrosalpinx which had burrowed in the broad ligament until it came in contact with the ovary. Within the ovary, lying in close contact with the hydrosalpinx, but separated from it by a thin complete septum, was a single cyst the size of a Tangerine orange, with a smooth lining. Evidently the condition was a stage in the formation of a tubo-ovarian cyst by the fusion of an ovarian cyst with a hydrosalpinx as described by Mr. Doran.

The production on each side of a cyst in the ovary which on the left side subsequently coalesced with the hydrosalpinx by absorption of the intervening septum to form a tubo-ovarian cyst can hardly have been a mere coincidence. The frequency of tubo-ovarian cysts is a strong argument against such a view. It seems to me rather that the ovarian cyst is produced by an interference with the ovarian circulation, due to the pressure of the burrowing hydrosalpinx on the ovarian lymphatic and blood-vessels. Any small previously-existing cyst in the ovary-for example, one of the corpus luteum or a dilated lymphatic-will form a fulcrum on which this increased lymph pressure can act in the formation of a large cyst. If the pressure within a thermometer be increased it is the bulb which will yield first.

The completion of Professor Guido Tizzoni's twentyfifth year of teaching was made the occasion of a graceful tribute from his colleagues throughout Italy and from his pupils in the University of Bologna. A committee presided over by Professor Vassale of Modena, presented him with a massive gold medal bearing on the obverse the name of the distinguished pathologist, and on the other the following inscription: "Guido Tizzoni-quod-in Athenaeo Bononiensi-Pathologiam generalem-Annos iam xxv-Summa ingeni laude tradiderit-Scriptis et inventis auxerit-Collegae discipuli-Prid. Kal. Iun. MCMVI." The students presented the Professor with an illuminated address on parchment.

The Consumption of Wine:-In his recent Budget speech the Chancellor of the Exchequer pointed out that within the last six years the consumption of wine in Great Britain has fallen nearly 50 per cent. In further illustration of this point the Wine Trade Review has published figures covering nearly the whole period which has elapsed since the term Gladstone claret first came into use, or in other words since the date, some forty-five years ago, when the duty on light wines was reduced much to its present figure. The statistics show that, though imports of Spanish wines had already fallen in 1900 by some 30 per cent., those of French and Portuguese varieties kept fairly steady until that date. Since then the fall of all three varieties has been so very rapid that the total consumption of all wines is now less by several million gallons than it was fortyfive years ago, in spite of the increase of population.

\section{ACHONDROPLASIA.}

\author{
BI
}

GUTHRIE RANKIN, AND ERNEST C. MACKAY, M.D., M.R.C.P.

PHISICIAN, DREADNOUGHT HOSPITAI AND ROYAL, WATERLOO M.B., B.S., RESIDENT MFDICAI, OFFICER, ROYAL, WATERLOO
HOSPITAL. HOSPITAL.

Achondroplasia, though a rare aisease, is of ancient origin. Dr. George Pernet ${ }^{1}$ has recently drawn attention to the fact that several Egyptian statues in the British Museum-notably one of the ancient god Pthah - clearly illustrate its characteristic deformities. Charcot and Richer ${ }^{2}$ bave also shown that many of the dwarfs at the Court of Philip IV who were painted by Velasquez were in all likelihood its victims.

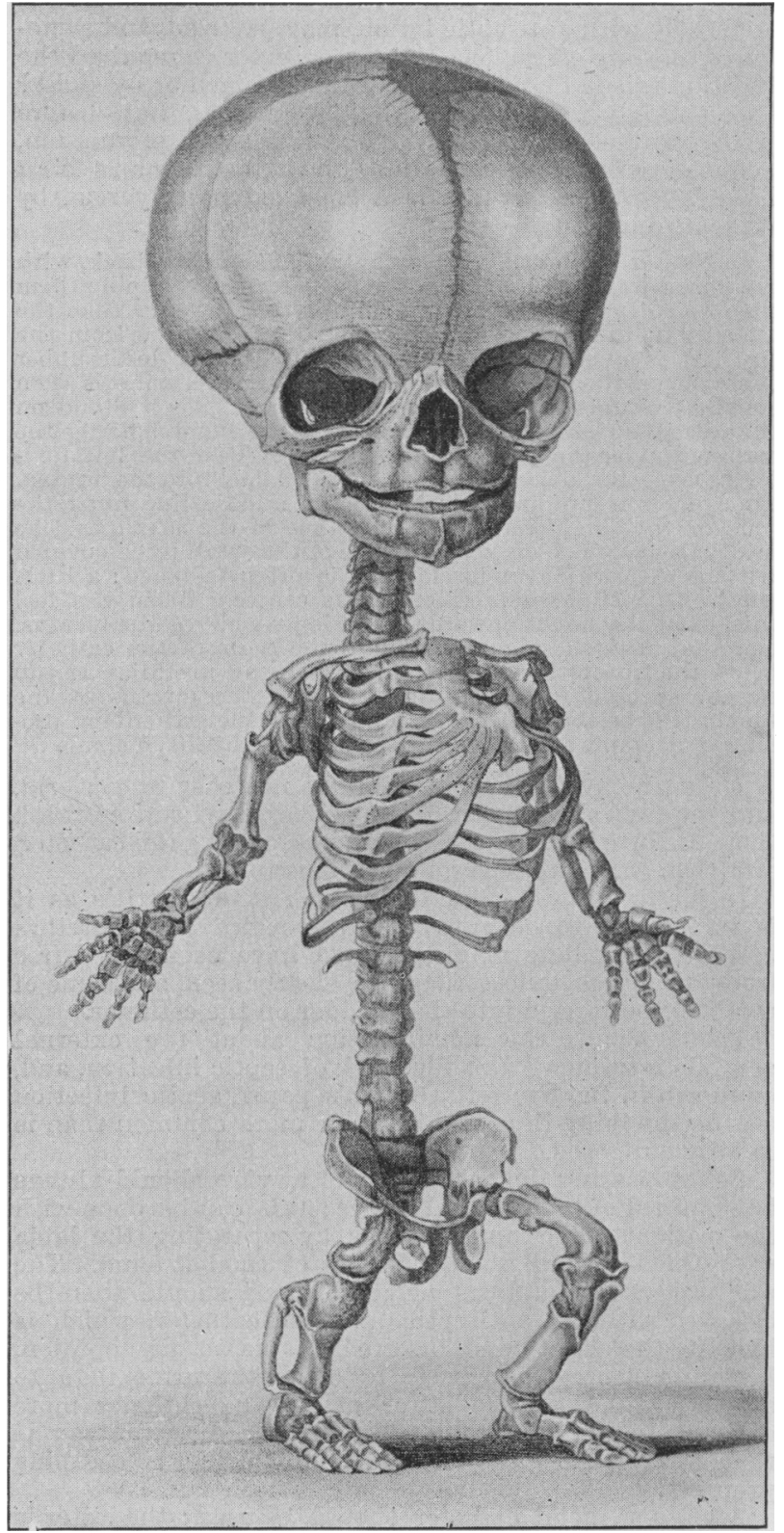

Fig. 1.-Reproduced from Liston's Elements of Surgery.

Though apparently uncommon, it probably occurs with considerable frequency, but has failed to attract attention because most cases are either stillborn or survive birth for but a short period. Formerly the survivors were mostly regarded as examples either of cretinism or rickets, and it was not until 1860 that the condition came to be recognized as a definite pathological entity. In that year Müller $^{3}$ published a series of careful observations which went to show that the disease is one of primordial 